http://ejtr.vumk.eu

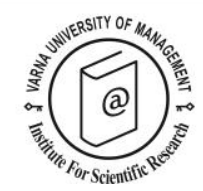

\title{
Business model complementarity in inbound tourism
}

\author{
Remigijus Kinderis ${ }^{1}$
}

Received: 13/11/2017

\begin{abstract}
1 Klaipeda University of Applied Sciences, Social Sciences Faculty, Tourism and Recreation Department; Jaunystes str.1, Klaipeda, Lithuania; phone: +37061483532; e-mail: r.kinderis@kvk.It
\end{abstract}

Supervisors: Professor Giedrius Jucevičius

Institution awarding the Ph. D. Degree: Kaunas University of Technology, Lithuania.

Date of defence: 05/06/2017

(C) 2018 Varna University of Management. All rights reserved

Citation: Kinderis, R. (2018) Business model complementarity in inbound tourism. Doctoral Dissertation Summary. European Journal of Tourism Research 19, pp. 140-144

\section{Goal and objectives of the dissertation Goal}

Goal of the dissertation - to determine the complementarity of business models and the factors that determine it in the inbound tourism.

\section{Objectives of the dissertation:}

1. Define the construct of the business model complementarity, systematise the conceptual insights of business models, interorganisational connections and complementarity.

2. Theoretically substantiate traits and characteristics of the business model complementarity and the factors that determine it in the inbound tourism, by preparing the conceptual model.

3. Substantiate methodology for the research of the business model complementarity and the factors that determine it in the inbound tourism.

4. Empirically identify and evaluate traits and characteristics of the business model complementarity and the factors that determine it in the Klaipeda city inbound tourism.

\section{Methodology}

In order to achieve the set objective, the most expedient thing was to follow the qualitative research strategy - the phenomenological case study, by applying an individual, targeted, semi-structured expert interview. Business model complementarity of travel organiser and its partners was considered as an intrinsic interpretative single case study with several units of analysis in the same context, expediently selected from the general set of business models of inbound tourism business sector. Case study analysis units were travel organiser and its partners (hotel, restaurant, carrier, and guide) that operate in Klaipeda city, and the research subjects are their managers. The method of targeted sample creation was employed in the dissertation - mixed targeted selection. In the given case, several methods of research sample identification were combined: selection of critical cases and criterial selection. 
The experts for the dissertation research were selected with respect to two criteria:

1) Documentary. The competence of the expert was evaluated according to the social information.

2) Self-evaluation of the expert. All experts were interested in the problem that was being examined and felt that they could provide data that is required for the information. (Yin, 2003; Lueg et al., 2016).

The case study research included two phases. During the performance of the first phase of the research, business models of travel organiser and its partners were analysed and the strategic choices that exist in them were identified with the help of semistructured interview of experts. Interview instrument was prepared by following business model structure, discerned by Osterwalder and Pigneur (2009), and its logical sequence, and the obtained research results were placed in the business model presentation instrument - business model canvas. In addition, the matrix of strategic choice measurement was employed, it helped identify the strategic choices that exist in the business model, by utilising a technique of semantic differential with a 7-point scale (with opposite characteristics). This matrix was prepared by integrating 9 groups of strategic choices that were discerned in the dissertation.

During the performance of the second phase of the research business model complementarity (characteristics: nature, intensity, orientation; identification characteristics) and the factors in Klaipeda city inbound tourism that determine it, were identified using other individual questionnaire of semi-structured interview, created according to the conceptual model of the business model complementarity and the factors that determine it.

Research data was presented in accordance with the linear-analytic method - the standard research report structure: analysis of a scientific literature, selection of methods, collection of data, its analysis, and presentation of conclusions and insights of further research guidelines. It is one of the most suitable methods for data presentation in the academic and scientific work (Runeson et al., 2012).

In order to substantiate and ensure the internal validity the researcher himself participated in the research, mechanical data recording and storage means were used; research report was presented to the research subjects (experts).

In order to substantiate and ensure the external validity, as detailed as possible description of the research and its report was provided (transcripts and abstracts of all 13 interviews).

\section{Results}

Complementarity is considered to be the result of interaction between the elements of company business model structure, when they strengthen/emphasize advantages of each other or reduce/eliminate disadvantages and together create higher value than when functioning individually. Complementary business models create complex adaptive business system due to the interaction of their similarities and differences, and form a distinctive configuration for the generating of the social and economic value.

Certain properties are characteristic to the business model complementarity in the context of strategic choices (nature, orientation and intensity) and the characteristics of identification.

According to the systemic point of view, the conceptual model of business model complementarity and the factors that determine it in the inbound tourism was presented. Model is comprised of three main components: analysis units of business model complementarity - business model elements; system of company business model complementarity criteria that helps to determine certain characteristics of complementarity in the context of strategic choices and characteristics of identification; as well as external and internal factors that determine the complementarity of company business models. 
The research of strategic choices in the business models of Klaipeda city inbound tourism companies showed that dominating strategic choices are related to: the creation of the product and the assurance of its quality, highlighting of advantages, assurance of human factor domination, direct personal sale; assurance of consumer loyalty and income from direct activity.

The research of traits and identification properties of the business model complementarity of Klaipeda city inbound tourism companies showed that:

- intensity of business model complementarity most strongly manifested between the following units of analysis: essential partnerships, value proposition, distribution/accessibility, consumer segment and the analysis of resources and abilities;

- business model complementarity is more intensive, when the same strategic choices are dominating;

- the nature of business model complementarity is "accumulative" due to the similarities of the dominating elements and the strategic choice compatibility in the business model.

The research of the factors that determine the complementarity of Klaipeda city inbound tourism company business models showed that the groups of internal factors determine the complementarity of business models more strongly than groups of external factors. The following groups of internal factors are active and determine business model complementarity:

- financial factors (transaction profitability), creation of high added value, effective use of resources;

- human factors (acquisition of new human resources (experience, abilities), improvement of competences (new knowledge, improvement);

- management factors (performance of obligations, improvement of marketing activity, improvement of quality, market expansion, appearance of new suppliers and intermediaries and maintenance of relations with them);

- physical-technological factors (maintenance of the service provision resources, acquisition of resources for the provision of new services, adhering to service provision standards and capabilities);

- organisational culture factors (change of values, following of provisions and obligations, change of norms, maintenance of mutual connections and relations, business philosophy, social responsibility, business ethics).

\section{Theoretical conclusions}

The analysis of the dissertation research results supplemented and confirmed that business model can be considered dynamic and static object at the same time: logical structure of actions and elements that helps to create a new value, a tool intended for the identification of the strategic choices of the organisation and for the analysis of company relations, activities and possibilities thereof.

Largest differences of the analysed business models manifested in the elements of: essential activities, main capabilities and resources, value proposition, and cost and income, and identical expression was recorded in the relations with consumers, units of the service provision and service consumer segment analysis.

Research results confirmed the levels, stages and orientations of business model interaction that were discerned in theory, because it was established that examined business models are open, one-two phased, and the main direction of activity is consumer oriented business (services).

The majority of the business model complementarity identification characteristics that were mentioned in the theoretical analysis have manifested and were identified. The following business model complementarity identification characteristics materialised and were confirmed: increased value proposition, increased number of consumers, improved reach of consumers, 
improved relations with consumers, activity configuration and concord, quicker decision making speed and higher competence, more effective use of resources, increased economy of activity.

The research allowed checking the validity of the widespread theoretical approaches that are used to explain why organisations form mutual relations and are prone to complementarity. The following approaches of the organisation cooperation interpretation were confirmed: transaction cost economy; resource sharing; strategic choice; relations development; the need of organisations to access the resources of other companies.

\section{Practical application of the dissertation}

The formed conceptual model in dissertation allows activity practitioners to understand systematicity of company business model complementarity even better, its essential traits, identification characteristics and factor the concord and importance. The obtained results of the research provide deeper insights and allows strengthening managerial impact to the creation and development of the potential partnerships. The research methodology for the business model complementarity and the factors that determine it in the inbound tourism is easily adaptable for the determination of business model complementarity of companies that operate in other business systems. Prepared research instrument is universal and can be considered as a diagnostic tool for interorganisational relations, it can be used to determine and evaluate the complementarity of company business models in various business systems.

\section{Content of the dissertation}

\section{Abstract of Chapter 1}

In the first chapter of the dissertation, the theoretically substantiated business model concept, structure and typology, concept of complementarity, scope of business model complementarity, theoretical characteristics, identification characteristics and factors in the inbound tourism are presented. The analysis of the inbound tourism structure is also provided, by adhering to the basis of the business model canvas, and the existing strategic choices are discerned. The main result of this section of the thesis - the conceptual model of the complementarity of company business models and the factors that determine it in the inbound tourism, was constructed (Osterwalder and Pigneur, 2009; Casadesus-Mansell and Ricart, 2010; Wirtz et al., 2016; Ennen and Richter, 2010; Batocchio et al., 2016).

\section{Abstract of Chapter 2}

The second chapter of the dissertation substantiates the methodology of the empirical research, based on the conceptual model of the complementarity of company business models and the factors that determine it in the inbound tourism that was prepared in the first section, by emphasizing the approach of the strategy of the qualitative research (Yin, 2003; Lueg et al., 2016; Bryman, 2016).

\section{Abstract of Chapter 3}

Third chapter of the dissertation presents the results of empirical research, by revealing the characteristics of complementarity, characteristics of identification and determining factors in the inbound tourism. The obtained results of the qualitative research allowed supplementing and partially checking the theoretical presumptions that were set in the dissertation, formulate the conclusions of the dissertation research, and provide the further research directions.

\section{References:}

Batocchio, A., Ghezzi, A., Rangone, A. (2016) A method for evaluating business models implementation process. Business Process Management Journal 22 (4), 712 $-735$.

Bryman, A. (2016) Social Research Methods. London: Oxford University Press.

Casadesus-Masanell, R. \& Ricart, J.E. (2010) From strategy to business models and onto tactics. Long Range Planning 43(23), 195-215.

Ennen, E., Richter, A. (2010) The Whole is More Than the Sum of Its Parts - Or is It? A Review of the Empirical Literature on 
Complementarities in Organizations. Journal of Management 36 (1), 207-233.

Lueg, K., Lueg, R., Andersen, K. and Dancianu, V. (2016) Integrated reporting with CSR practices: a pragmatic constructivist case study in a Danish cultural setting. Corporate Communications: An International Journal 21 (1), 2035.

Osterwalder, A., \& Pigneur, Y. (2009) Business model generation: $A$ handbook for visionaries, game changers, and challengers. Self-published.
Runeson, P., Host, M., Rainer A., and Regnell, B. (2012) Case Study Research in Software Engineering - Guidelines and Examples. USA: Wiley.

Wirtz, B., Pistoia, A., Ullich, S. \& Göttel, V. (2016) Business models: Origin, development and future research perspectives. Long Range Planning 49, 36-54.

Yin, R.K. (2003) Case study research: Design and methods (3rd ed.). Thousand Oaks, CA: Sage. 